\section{AiCS}

How to cite this article: Santos et al. Perineal trauma in nulliparous women and its associated factors. ABCS Health Sci. 2021;46:e021224. https://doi.org/10.7322/ abcshs.2020047.1496

Received: May 22, 2020

Revised: Oct 29, 2020

Approved: Dec 08, 2020

Corresponding Author: Caroline Wanderley Souto Ferreira - Departamento de

Fisioterapia, Centro de Ciências da Saúde, Universidade Federal de Pernambuco -

Avenida Professor Moraes Rego, 1235

- Cidade Universitária - CEP: 50670-901

- Recife (PE), Brazil -

E-mail: caroline.wanderley@ufpe.br;

caroline.wanderley@hotmail.com

Declaration of interests: nothing to declare

This is an open access article distributed under the terms of the Creative Commons Attribution License

(C2021 The authors

\title{
Perineal trauma in nulliparous women and its associated factors
}

\author{
Rebeca Vieira dos Santos ${ }^{1}$, Alianny Raphaely Rodrigues Pereira ${ }^{1}$, Cláudia Regina \\ Oliveira de Paiva Lima ${ }^{2}$, Diego de Sousa Dantas ${ }^{1}$, Caroline Wanderley Souto Ferreira ${ }^{1}$ \\ ${ }^{1}$ Departamento de Fisioterapia, Universidade Federal de Pernambuco (UFPE) - Recife (PE), Brazil \\ 2Departamento de Estatística, UFPE - Recife (PE), Brazil
}

\begin{abstract}
Introduction: Perineal trauma is an important complication for women after giving birth. Objective: To evaluate the prevalence of perineal trauma and its associated factors in nulliparous. Methods: A retrospective cohort study was carried out, through the analysis of the medical records of women with singleton pregnancy who achieved vaginal birth of a live infant, in 2017, in a maternity hospital. Data collection involved information about demographic, obstetric, and clinical data from nulliparous women, and infant birthweight. Univariate and multivariate logistic analyses were performed to verify the association of perineal trauma with the variables assessed, with significant variables remaining in the model $(\mathrm{p}<0.05)$, through a stepwise strategy. Results: A total of 326 medical records were analyzed. The percentage of perineal trauma was $60 \%$. In the multivariate analysis, the use of oxytocin increased the chance of perineal trauma by $730 \%$. In addition, the adoption of squatting position and hands and knees decreased the chances of perineal trauma by $81 \%$ and $97 \%$, respectively, in comparison with those who adopted the lithotomy position, during the second stage labor. Conclusion: The rate of perineal laceration was high, but the severity was low. The use of oxytocin is associated with the presence of trauma and the squatting position and hands and knees, especially, have contributed to the protection of the perineum.
\end{abstract}

Keywords: perineum; oxytocin; posture; birth injuries; episiotomy.

\section{INTRODUCTION}

Despite the many benefits of vaginal birth, this procedure must be very well conducted to avoid pelvic floor injuries. Complications due to perineal trauma can happen immediately, such as pain, hemorrhage, infection, and trauma of the pelvic floor muscles, as well as belatedly, such as sexual dysfunction, urinary and/or fecal incontinence. Any of these complications will negatively impact a women's daily and professional life activity ${ }^{1}$.

During the 1960's, many studies about the effect of maternal posture during labor on important outcomes for the parturient women and the fetus were published ${ }^{2,3}$. In a Cochrane review involving 22 studies and 7,280 women, it was found that vertical positions in labor resulted in a decrease of $12 \%$ in assisted births and lowered the incidence of episiotomy, when compared to supine posture ${ }^{4}$.

Spontaneous lacerations are classified as first degree when they affect the skin and mucosa; second degree when they extend to the perineal muscles; third degree when 
they reach the sphincter muscle of the anus; and fourth degree when the lesion of the perineum involves the anal sphincter and epithelium. In episiotomy, a surgical enlargement of the posterior face of the vagina leads to damage to the skin and mucosa; as well as the superficial transverse muscles of the perineum and bulbocavernosus ${ }^{5}$.

To decrease the incidence of third- and fourth-degree lacerations, the American College of Obstetricians and Gynecologists recommends the application of warm perineal compresses during pushing (with a level A rating of evidence) and perineal massage during the second stage of labor (with a level $B$ rating of evidence $)^{5}$.

Since perineal trauma is a serious complication for women after giving birth, it is important to find how to prevent it; so, the objective of this study is to evaluate the prevalence of perineal trauma and its associated factors in nulliparous women.

\section{METHODS}

It is a retrospective cohort study, performed through secondary analysis of medical records of women who gave birth in 2017, in a maternity hospital in the city of Recife, Pernambuco, Brazil. This study complied with the standards required by Resolution 466/12 of the Brazilian Health Council and was approved by the Human Research Ethics Committee of Universidade Federal de Pernambuco, in 02/10/2018, under CAAE: 98416818.7.0000.5208.

The sample size calculation was performed considering a prevalence of $45.5 \%$ for spontaneous perineal trauma ${ }^{6}$, a rate of 2400 deliveries per year, an average of 200 deliveries per month at the maternity hospital of the study, a standard error of $5 \%$ and a confidence level of 95\%, resulting in a sample of 326 medical records.

For the selection of medical records, a systematic random sampling was adopted. The first one was selected followed systematically by every six patients. When the medical record did not meet the eligibility criteria, the next record was used. The medical records were organized by date of delivery.

In this study, medical records of women with singleton pregnancy who achieved vaginal birth of a live infant were included. Medical records of women with a history of previous childbirth and/or gynecological surgery, as well as medical records with incomplete or missing data were excluded.

One form with socio-demographic, obstetric and gynecological information was used to collect data. The dependent variable was the presence perineal trauma. The independent variables were: maternal age, gestational age (preterm: less than 37 weeks; term: from 37 weeks to less than 42 complete weeks; post-term: 42 complete or more weeks of gestation); oxytocin, use of pharmacological analgesia, maternal position during birth, forceps usage, infant birthweight, episiotomy, presence of perineal trauma and grade $\left(1^{\text {st }}, 2^{\text {nd }}, 3^{\text {rd }} \text { and } 4^{\text {th }} \text { degree laceration }\right)^{5}$. The women's ages were organized into three age groups (group 1: 11-19; group 2: 20-34; and group 3: from 35 years old). The infant birthweight was given in grams (g) and it was categorized into three groups: low (below 2,500g); appropriate (from 2,500g to $3,999 \mathrm{~g}$ ) and high (greater than or equal to $4,000 \mathrm{~g})^{7}$.

Statistical analysis was performed using the Statistical Package for the Social Sciences (SPSS), version 20.0. Data were given as means and their standard deviations for quantitative variables. Some of these variables were categorized and then the absolute and relative frequencies were obtained. To analyze the association between perineal trauma and independent variables, bivariate regression was initially performed, and then multiple logistic regression analysis was performed using the stepwise method to select the variables. In both analyses, the Risk Ratio, 95\% Confidence Interval and 5\% significance level were calculated.

\section{RESULTS}

Out of 567 records selected, 326 were analyzed (Figure 1). The sample age ranged from 11 to 37 years, with mean and standard deviation of $22.08 \pm 5.35$ years and $74 \%$ completed high school. Most women gave birth at term (98\%), did not use oxytocin $(80 \%)$, did not use analgesia (95\%), did not need forceps (99\%), nor episiotomy (87\%) and placed themselves in lithotomy in the expulsive period (79\%). The prevalence of perineal trauma was $60 \%$ (194). Of these 194 women, 52\% were classified as first grade and $46 \%$ did not have the grade of laceration recorded in the medical records (Table 1).

The infant birthweight had a mean and standard deviation of $2,923 \pm 771.55 \mathrm{~g}$, with a minimum value of 1,300 and a maximum value of 4,300 g. Most of them were classified as normal weight (70\%) (Table 2).

The univariate and multivariate logistic regression analyses are shown in Table 3. In the multivariate analysis, only the variables oxytocin usage and Maternal position at second stage of labor were statistically significant. It was observed that women who adopted the positions hands and knees and squatting were $97 \%$ and $81 \%$, respectively, less likely to have perineal trauma than those

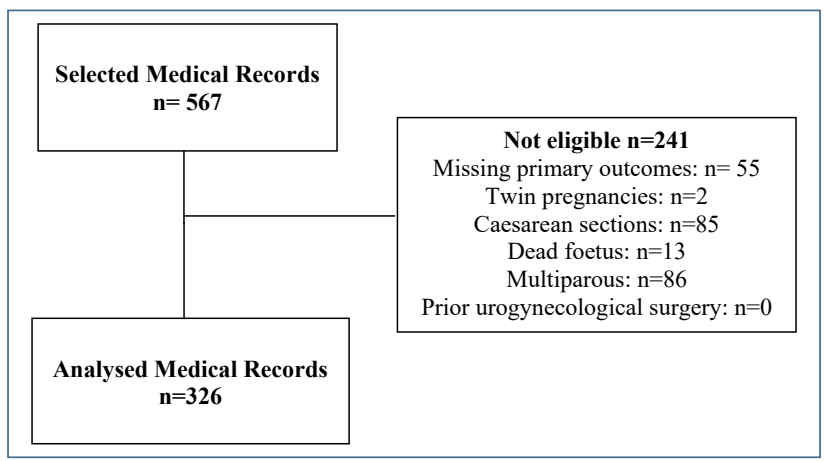

Figure 1: Sampling process flowchart. 
Table 1: Socio-demographic, obstetric and gynecological characteristics of the parturient.

\begin{tabular}{|c|c|c|}
\hline Variables & $\begin{array}{c}\text { Number } \\
\text { (n) }\end{array}$ & $\begin{array}{c}\text { Percentage } \\
(\%)\end{array}$ \\
\hline \multicolumn{3}{|l|}{ Maternal Age (years) } \\
\hline $11-19$ & 118 & 36 \\
\hline $20-34$ & 200 & 61 \\
\hline $35-37$ & 8 & 3 \\
\hline \multicolumn{3}{|l|}{ Maternal education (Years of study) } \\
\hline 12 & 242 & 74 \\
\hline 9 & 84 & 26 \\
\hline \multicolumn{3}{|l|}{ Gestational age } \\
\hline Preterm (<37 weeks) & 7 & 2 \\
\hline Term (from 37 to $<42$ complete weeks) & 319 & 98 \\
\hline \multicolumn{3}{|l|}{ Oxytocin usage } \\
\hline Yes & 64 & 20 \\
\hline No & 262 & 80 \\
\hline \multicolumn{3}{|l|}{ Analgesia usage } \\
\hline Yes & 17 & 5 \\
\hline No & 309 & 95 \\
\hline \multicolumn{3}{|l|}{ Maternal position at second stage } \\
\hline Lithotomy & 258 & 79 \\
\hline Squatting & 17 & 5 \\
\hline Hands-and-knees & 13 & 4 \\
\hline Not specified & 38 & 12 \\
\hline \multicolumn{3}{|l|}{ Forceps usage } \\
\hline Yes & 2 & 1 \\
\hline No & 324 & 99 \\
\hline \multicolumn{3}{|l|}{ Episiotomy } \\
\hline Yes & 43 & 13 \\
\hline No & 283 & 87 \\
\hline \multicolumn{3}{|l|}{ Perineal injury } \\
\hline Yes & 194 & 60 \\
\hline No & 132 & 40 \\
\hline \multicolumn{3}{|l|}{ Laceration grade } \\
\hline $1^{\circ}$ grade & 102 & 52 \\
\hline $2^{\circ}$ grade & 0 & 0 \\
\hline $3^{\circ}$ grade & 2 & 1 \\
\hline $4^{\circ}$ grade & 1 & 1 \\
\hline Not specified & 89 & 46 \\
\hline
\end{tabular}

Table 2: Infant birthweight.

\begin{tabular}{|l|c|c|}
\hline Infant birthweight $(\mathbf{g})$ & Number $(\mathbf{n})$ & Percentage (\%) \\
\hline Low $(<2,500)$ & 89 & 27 \\
\hline Appropriate $(2,500-3,999)$ & 228 & 70 \\
\hline High $(\geq 4,000)$ & 9 & 3 \\
\hline
\end{tabular}

who adopted the lithotomy position, during the expulsive period. Women who used oxytocin were 8.3 times (730\%) more likely to have perineal trauma (Table 3 ).

\section{DISCUSSION}

In this study, it was found that the prevalence of perineal trauma was $60 \%$. The use of oxytocin in labor increased the chances of perineal trauma by 8.3 times or $730 \%$, while the adoption of hands and knees and squatting positions decreased the chances of perineal trauma, by $97 \%$ and $81 \%$, respectively, in comparison with those who adopted the lithotomy position, during the expulsive period.

Although other variables, such as age between 11 and 19 years, episiotomy, and infant birthweight were initially associated with the outcome, in the multivariate logistic regression model, they lost their association.

The perineal trauma rate of this study was high (60\%) when compared to other studies ${ }^{8,9}$. In these studies ${ }^{8,9}$, the prevalence found was $25 \%$ and $4.5 \%$ respectively, the authors evaluated the prevalence and risk factors for severe perineal trauma, in other words, third and fourth degree. In the present study, we did not restrict the degree of laceration and the study population had as its main characteristic, being nulliparous, which contributed to a higher percentage of this obstetric trauma, thus reinforcing the evidence that primiparity predisposes women to perineal trauma ${ }^{5,10}$.

Even though the use of oxytocin during labor is an obstetric violence, it is still a common practice to reduce the time of labor, especially in nulliparous women, where the birth is usually longer, more difficult, and more likely to present complications ${ }^{11}$. Although in the present study the rate of oxytocin usage was not acceptable, it was low (20\%) compared with others, reaching more than $40 \%^{12}$, the use of oxytocin considerably increased the chances of perineal trauma. This fact may be explained by the action of oxytocin, which, depending on plasma levels, may lead to overstimulation of the uterus causing an abrupt cephalic detachment, resulting in perineal trauma ${ }^{13}$.

Regarding the position adopted in the expulsive phase, in the present study, it is evident that women who gave birth in lithotomy presented a higher percentage of perineal trauma, while squatting and hands and knees positions were responsible for a lower incidence of this obstetric outcome, being considered protective positions.

Our results are in line with previous research, that states that vertical position during vaginal birth is a factor that favors the action of gravity on fetal displacement, increasing fetal body pressure on the lower pelvis and uterine cervix; also increasing the intensity and frequency of contractions, making them more effective and thus contributing to a shorter duration of labor, with a consequent decrease in the risk of perineal trauma and instrumental birth ${ }^{14,15}$.

The squatting position offers numerous benefits to women during birth labor, as it increases the anteroposterior and transverse diameters of the pelvis, favors greater comfort to the parturient, in addition to widening the lower pelvis, decreasing the tension of the pelvic floor muscles ${ }^{16,17}$.

Although there are not many studies checking the association between the hands and knees posture, during the second stage of 
Table 3: Association of laceration prevalence with variables analyzed.

\begin{tabular}{|c|c|c|c|c|c|c|}
\hline \multirow{2}{*}{ Variables } & \multirow{2}{*}{$\begin{array}{c}\text { With Laceration } \\
\mathrm{n}(\%)\end{array}$} & \multirow{2}{*}{$\begin{array}{c}\text { Without Laceration } \\
\mathbf{n}(\%)\end{array}$} & \multicolumn{2}{|c|}{ Univariate analysis } & \multicolumn{2}{|c|}{ Multivariate analysis } \\
\hline & & & OR [CI 95\%] & $\mathbf{p}$ & OR [Cl 95\%] & $\mathbf{p}$ \\
\hline \multicolumn{7}{|l|}{ Gestational age } \\
\hline Pre-term & $3(43)$ & $4(57)$ & & 0.36 & - & - \\
\hline Term & $191(60)$ & $128(40)$ & $1.99[0.44 ; 9.04]$ & & & \\
\hline \multicolumn{7}{|l|}{ Oxytocin usage } \\
\hline Yes & $58(91)$ & $6(9)$ & $8.96[3.73 ; 21.48]$ & $<0.01$ & $8.3[3.06 ; 22.49]$ & $<0.01$ \\
\hline No & $136(52)$ & $126(48)$ & & & & \\
\hline \multicolumn{7}{|l|}{ Analgesia usage } \\
\hline Yes & $17(100)$ & $0(0)$ & $1.2 \times 10^{9}\left[{ }^{\star}\right]$ & $>0.99$ & - & - \\
\hline No & $177(57)$ & $132(43)$ & & & & \\
\hline \multicolumn{7}{|c|}{ Maternal position at second stage $\mathrm{e}^{\&}$} \\
\hline Squatting & $4(24)$ & $13(76)$ & $0.14[0.04 ; 0.45]$ & 0.01 & $0.19[0.06 ; 0.63]$ & 0.01 \\
\hline Hands-and-knees & $1(8)$ & $12(92)$ & $0.04[0.01 ; 0.30]$ & 0.04 & $0.03[0.01 ; 0.33]$ & $<0.01$ \\
\hline Lithotomy & $176(68)$ & $82(32)$ & & & & \\
\hline \multicolumn{7}{|l|}{ Episiotomy } \\
\hline Yes & $39(91)$ & $4(9)$ & $8.05[2.80 ; 23.13]$ & $<0.01$ & - & - \\
\hline No & $155(55)$ & $128(45)$ & & & & \\
\hline \multicolumn{7}{|l|}{ Forceps usage } \\
\hline Yes & $2(100)$ & $0(0)$ & $1.1 \times 10^{9}\left[{ }^{\star}\right]$ & 0.52 & - & - \\
\hline No & $192(59)$ & $132(41)$ & & & & \\
\hline \multicolumn{7}{|l|}{ Infant birthweight } \\
\hline Low $(<2500)$ & $40(45)$ & $49(55)$ & & & & \\
\hline Appropriate (2500-3999) & $148(65)$ & $80(35)$ & $2.27[1.38 ; 3.73]$ & $<0.01$ & - & - \\
\hline High $(\geq 4000)$ & $6(67)$ & $3(33)$ & $2.45[0.58 ; 10.42]$ & 0.22 & - & - \\
\hline \multicolumn{7}{|l|}{ Maternal Age (years) } \\
\hline $11-19$ & $80(68)$ & $38(32)$ & $1.69[1.05 ; 2.72]$ & 0.03 & - & - \\
\hline $20-34$ & $111(56)$ & $89(44)$ & & & & \\
\hline $35-37$ & $3(38)$ & $5(62)$ & $0.48[0.11 ; 2.07]$ & 0.32 & - & - \\
\hline \multicolumn{7}{|c|}{ Maternal education (Years of study) } \\
\hline 9 & $56(67)$ & $28(33)$ & $0.66[0.39 ; 1.12]$ & 0.12 & - & - \\
\hline 12 & $138(57)$ & $104(43)$ & & & & \\
\hline
\end{tabular}

${ }^{\&} \mathrm{~N}=288,38$ missing data. $\mathrm{n}$ : Absolute frequency; \%: Relative frequency; OR: Odds Ratio; Cl: Confidence interval; binary regression and multiple regression analysis; $\mathrm{p}<0.05$. *Not submitted to statistical test for presenting a quad without observation.

labor, and the perineal trauma, this posture brings many benefits for women and fetus during labor ${ }^{18}$. Among them, it enables a better perception of the pelvic movement ${ }^{19}$.

The hands and knees posture decreases the low back pain during labor, and there is little evidence of its association with perineal protection. However, it is believed that it helps in the relaxation of the pelvic floor, due to the better fitting of the femoral head in the acetabular space, during flexion of the hip joint ${ }^{20}$.

As for the biomechanical benefits that this position offers, some authors claim that the pelvis resting on the femoral heads allows it to be freer, the iliac bones can better adapt to the shape of the fetus, and the sacrum is also free, allowing movements of nutation and counternutation. Moreover, when the fetal head is seated, this position can facilitate fetal unwinding during passage through the birth canal and during detachment, the pelvis fits better with the foetus ${ }^{21}$.

It was shown that most parturient adopted the lithotomy posture, during the expulsive period, which seems to be a cultural problem and a lack of knowledge, as well, on the part of women and health professionals. In a preliminary study ${ }^{22}$ on the culture of immobilization in parturient women, it was evidenced that most professionals discussed and guided the birth positions, but the position most chosen by women was lithotomy, because of the lack of knowledge of other positions and because it is culturally the most common. The study also reported the resistance of health professionals to encourage women to adopt vertical postures during labor.

As the female pelvis ages and develops, fusion of sequential bone structures occurs ${ }^{23}$ and structural underdevelopment of the pelvis would increase the chances of trauma to the pelvic floor of adolescent or younger women, but in the present study there was no association of maternal age with the occurrence of perineal trauma.

In the literature, variables such as gestational age ${ }^{5}$, high infant birthweight ${ }^{24,25}$, use of forceps ${ }^{26}$ and use of analgesia ${ }^{27,28}$ are associated with perineal trauma. However, in this study these associations were not confirmed, probably due to the low occurrence of these outcomes.

The episiotomy rate in the present study was not low (13\%); however, it shows that the use of episiotomy as a routine procedure 
is decreasing, since in the literature the rates of use of this procedure in nulliparous are much higher $(94.2 \%)^{28}$. Therefore, we conclude that the maternity did not use episiotomy routinely but selectively, as recommended by the Ministry of Health ${ }^{7}$, because this procedure, when used, already causes second degree laceration $^{29}$. In a previous study with 40 nulliparous submitted to routine or selective episiotomy, it was found that $80 \%$ of the selective group had intact perineum or suffered first degree laceration, thus evidencing that the use of selective episiotomy favors the reduction of perineal trauma ${ }^{30}$.

A limitation of our study was the missing data in some outcomes, that is the duration of the second stage of labor; and the lack of notification of the degree of laceration in $46 \%$ of nulliparous. However, it is something expected in retrospective studies, using medical records; so, it wasn't possible to check the association between duration of the second stage of labor with perineal trauma, which has already been shown ${ }^{6,31}$.

The strengths of our study were the right sample size, the randomization to select the medical records and the robust statistical analyses that enabled us to be confident about the results.

\section{Conclusion}

The prevalence of perineal trauma was $60 \%$ and the practice of using oxytocin in labor increased the chance of perineal trauma by 8.3 times or $730 \%$. On the other hand, the adoption of hands and knees and squatting positions during labor decreased the chances of perineal trauma, by $81 \%$ and $97 \%$, respectively, in comparison with those who adopted the lithotomy position, during the second stage labor.

These findings bring new relevant data to the discussion of the health professionals that performs childbirth care, with a view to the adoption, whenever clinically viable, of feasible practices such as the modification of the posture of childbirth, with the stimulation of the hands and knees and squatting positions, and the rational use of oxytocin in order to reduce the occurrence of perineal trauma.

\section{ACKNOWLEDGMENTS}

The Authors wish to thank the support given buy the maternity staff during data collection and Mr. Craig Bernard Donnelly for proofreading the manuscript.

\section{REFERENCES}

1. Moore KL, Dalley AF, Agur AMR. Anatomia orientada para a clínica. 7 ed. Rio de Janeiro: Guanabara Koogan, 2014.

2. Russel JG. Moulding of the pelvic outlet. Obstet Gynaecol Br Commonw. 1969;76(9):817-20. https://doi.org/10.1111/j.1471-0528.1969.tb06185.x

3. Mitie IN. The influence of maternal position on duration of the active phase of labor. Int J Gynaecol Obstet. 1974;12(5):181-3. https://doi.org/10.1002/j.1879-3479.1974.tb00945

4. Kemp E, Kingswood CJ, Kibuka M, Thornton JG. Position in the second stage of labor for women with epidural anaesthesia. Cochrane Database Syst Rev. 2013;(1):CD008070. https://doi.org/10.1002/14651858.CD008070.pub2

5. Committee on Practice Bulletins-Obstetrics. ACOG Practice Bulletin no. 198: prevention and management of obstetric lacerations at vaginal delivery. Obstet Gynecol. 2018;132(3):e87-102 https://doi.org/10.1097/AOG.0000000000002841

6. Riesco MLG, Costa ASC, Almeida SFS, Basile ALO, Oliveira SMJV. Episiotomia, laceração e integridade perineal em partos normais: análise de fatores associados. Rev Enferm UERJ. 2011:19(1):77-83

7. Brasil. Ministério da Saúde. Secretaria de Ciência, Tecnologia e Insumos Estratégicos. Departamento de Gestão e Incorporação de Tecnologias em Saúde. Diretrizes Nacionais de Assistência ao Parto Normal. Brasília: Ministério da Saúde, 2017.

8. Hals E, Oian P, Pirhonen T, Gissler M, Hjelle S, Nilsen EB, et al. A multicenter interventional program to reduce the incidence of anal sphincter tears. Obstet Gynecol. 2010;116(4):901-8. https://doi.org/10.1097/AOG.0b013e3181eda77a
9. Groutz A, Hasson J, Wengier A, Skornick-Rapaport A, Lessing JB, Gordon D. Third- and fourth-degree perineal tears: prevalence and risk factors in the third millennium. Am J Obstet Gynecol. 2011:204(4):P347.e1-347.e4.

https://doi.org/10.1016/j.ajog.2010.11.019

10. Francisco AA, Oliveira SMJV, Santos JO, Silva FMB. Avaliação e tratamento da dor perineal no pós-parto vaginal. Acta Paul Enferm. 2011;24(1):94-100. https://doi.org/10.1590/S0103-21002011000100014

11. Hidalgo LP, Hidalgo MM, Rodrigues BMA. Labor stimulation with oxytocin: effects on obstetrical and neonatal outcomes. Rev Latino-Am Enfermagem. 2016;(24):27-44 https://doi.org/10.1590/1518-8345.0765.2744

12. Oliveira LB, Mattos DV, Matão MEL, Martins CA. Laceração perineal associada ao uso de ocitocina exógena. Rev Enferm UFPE. 2017:8(1):2273-8.

https://10.5205/1981-8963-v11i6a23387p2273-2278-2017

13. Jonsson M. Induction of twin pregnancy and the risk of caesarean delivery: a cohort study. BMC Pregnancy Childbirth. 2015;15:136. https://doi.org/10.1186/s12884-015-0566-4

14. Lawrence A, Lewis L, Hofmeyr GJ, Dowswell T, Styles C. Maternal positions and mobility during first stage labor. Cochrane Database Syst Rev. 2009;(2):CD003934. https://doi.org/10.1002/14651858.CD003934.pub2

15. Gizzo S, Gangi S, Noventa M, Bacile V, Zambon A, Nardeli GB Women's choice of positions during labor: return to the past or a modern way to give birth? A cohort study in Italy. Biomed Res Int. 2014:2014:638093.

https://doi.org/10.1155/2014/638093 
16. Calais GB. O períneo feminino e o parto. Elementos de anatomia e exercícios práticos. São Paulo: Manole, 2005.

17. Kapandiji IA. Fisiologia articular: Esquemas comentados de mecânica humana. 6 ed. Rio de Janeiro: Guanabara Koogan, 2009.

18. Freitas JMS, Narchi NZ, Fernandes RAQ. Práticas obstétricas em centro de parto normal intra-hospitalar realizadas por enfermeiras obstetras. Esc. Anna Nery. 2019:23(4):e20190112. https://doi.org/10.1590/2177-9465-2019-0112

19. Lemos A. Fisioterapia obstétrica baseada em evidência. Rio de Janeiro: MedBook, 2014.

20. Lee DG, Hodges P. The pelvic girdle: an approach to the examination and treatment of the lumbopelvic-hip region. 3rd ed. United Kingdom: Churchill Livings-Tone, 2004.

21. Calais GB, Parés N. A pelve feminina e o parto. São Paulo: Manole, 2013.

22. Leal MC, Bittencourt SA, Esteves-Pereira AP, Ayres BVS, Silva LBRAA, Thomaz EBAF, et al. Avanços na assistência ao parto no Brasil: resultados preliminares de dois estudos avaliativos. Cad Saude Publica. 2019;35(7):e00223018. https://doi.org/10.1590/0102-311×00223018

23. Stenpheson R, O'Conner L. Obstetric and gynecological care in physical therapy. Second Ed. Slack, EUA: Slack, 2000.

24. Koyanagi A, Zhang J, Dagvador A, Hirayama F, Shibuya K, Souza $\mathrm{JP}$, et al. Macrosomia in 23 developing countries: An analysis of a multicountry, facility-based, cross-sectional survey. Lancet. 2013;381(9865):476-83

https://doi.org/10.1016/S0140-6736(12)61605-5
25. Gyurkovits Z, Kálló K, Bakki J, Katona M, Bitó T, Pál A, et al Neonatal outcome of macrosomic infants: An analysis of a two-year period. Eur J Obstet Gynecol Reprod Biol. 2011;159(2):289-92. https://doi.org/10.1016/j.ejogrb.2011.08.003

26. Simic M, Cnattingius S, Petersson G, Anna Sandström A, Stephansson O. Duration of second stage of labor and instrumental delivery as risk factors for severe perineal lacerations: populationbased study. BMC Pregnancy Childbirth. 2017;17(1):72. https://doi.org/10.1186/s12884-017-1251-6

27. Smith LA, Price N, Simonite V, Burns EE. Incidence of and risk factors for perineal trauma: a prospective observational study. BMC Pregnancy Childbirth. 2013;13:59. https://doi.org/10.1186/1471-2393-13-59

28. Althabe F, Belizan JM, Bergel E. Episiotomy rates in primiparous women in Latin American: hospital based descriptive study. BMJ. 2002;324(7343):945-46.

https://doi.org/10.1136/bmj.324.7343.945

29. Amorim MM, Franca-Neto FA, Leal VM. Is it possible to never perfom episiotomy during vaginal delivery?. Obstet Gynecol. 2014;385.

https://doi.org/10.1097/01.AOG.0000447314.51968.54

30. Shahraki AD, Aram S, Pourkabirian S, Khodaee S, Choupannejad S. A comparison between early maternal and neonatal complications of restrictive episiotomy and routine episiotomy in primiparous vaginal delivery. J Res Med Sci. 2011;16(12):1583-9.

31. Loewenberg-Weisband Y, Grisaru-Granovsky S, Ioscovich A, Samueloff A, Calderon-Margalit R. Epidural analgesia and severe perineal tears: a literature review and large cohort study. J Matern Fetal Neonatal Med. 2014;27(18):1864-9. https://doi.org/10.3109/14767058.2014.889113 